\title{
TEMPORARY VESICOSTOMY IN CHILDREN WITH VOIDING DYSFUNCTION: POSSIBLE PREDICTORS OF MORPHOLOGICAL AND FUNCTIONAL IMPROVEMENT OF UPPER URINARY TRACT
}

\author{
By
}

\author{
Ahmed H. Okasha, Hussein A. Galal, and El-Sayed M. Salih \\ Department of Urology, Faculty of Medicine, Al-Azhar University (Cairo)
}

Corresponding author: Ahmed $\mathrm{H}$. Okasha,

Mobile: 01008072741, E-mail: aokasha2016@gmail.com

\begin{abstract}
Background: Chronic retention in infancy and childhood is induced secondary to lower urinary tract obstruction or dysfunction.

Objectives: To evaluate the outcomes of temporary vesicostomy in children with voiding dysfunction, and to assess the possible predictors of morphological and functional improvement of upper urinary tract.

Patients and Methods: This retrospective study included 69 patients who underwent cutaneous vesicostomy during the period from January 2014 to December 2019 at Al-Azhar University hospitals (Al-Hussein and Sayed Galal) Cairo; Egypt. Patients were evaluated by clinical history, examination, urine analysis, s.creatinine, ultrasonography, voiding cystourethrogram, magnetic resonance urography and renal scan before and 12 months after vesicostomy.

Results: There was significant clinical, morphological and functional improvement. The mean serum creatinine before vesicostomy was $1.75 \pm 1.12 \mathrm{mg} / \mathrm{dl}$ and improved gradually to $0.97 \pm 0.63 \mathrm{mg} / \mathrm{dl}$ after 12 months. Number of pus cells decreased gradually from $44.35 \pm 33.23$ cell/ HPF to $2.65 \pm 1.74$ cell/ HPF. The mean glomerular filtration rate (GFR) was $25.0 \pm 11.5$ and $50.8 \pm 21.7 \mathrm{ml} /$ minute pre and 12 months after vesicostomy respectively. Forty four $(63.8 \%)$ cases were not complicated, $7(10.1 \%)$ cases (5 male and 2 females) were complicated with prolapse, $8(11.6 \%)$ cases complicated with stenosis and all of them were males, and $10(14.5 \%)$ cases complicated with peristomal dermatitis and all of them were males.

Conclusion: Vesicostomy is a simple urinary diversion, showing encouraging results towards safeguard of kidney function and morphology. Furthermore, the procedure has received rave reviews from the caregivers, and therefore, it has become a viable choice for children with neurological or other voiding dysfunctions or those that do not respond to conservative treatment.
\end{abstract}

Key words: Temporary Vesicostomy, children, voiding dysfunction, morphological, functional improvement, upper urinary tract

\section{INTRODUCTION}

Chronic retention in infancy and childhood is induced secondary to lower urinary tract obstruction or dysfunction. The commonest causes are posterior urethral valves, neurogenic bladder dysfunction DEW (myelomeningocele), anterior urethral obstruction, prune belly syndrome and miscellaneous causes as following pelvic surgery (Howe et al., 2017).

There are variety of management modalities either primary treatment of the 
etiological factor especially in early noncomplicated cases or temporary diversion especially in complicated cases (massive reflux, hydronephrosis, urosepsis) until the upper tract is stabilized then definitive treatment of the etiological factor is performed (Coran et al. 2012). Treatments include physiotherapy, Clean Intermittent Catheterization (CIC), and anti-cholinergic drugs; surgery is considered if medical treatment has failed (Rouzrokh et al., 2013).

Improvement of reconstructive techniques in pediatric urology and the introduction of clean intermittent catheterization (CIC) have greatly facilitated the management of patients with vesical and urethral disorders and reduced the frequency of urinary diversion. Temporary diversion is occasionally still the best means of preserving renal function and allowing ultimate reconstruction in children with disorders of the upper and lower urinary tract (Lopes and Lorenzo, 2016).

Vesicostomy in myelodysplastic
children is effective in
preventing/resolving the deleterious
consequences of a hostile bladder.
Neonates with posterior urethral valve (PUV) and non-responders to catheter drainage also are candidates for a vesicostomy procedure. Vesicostomy is a simple surgery that protects upper urinary tract, decreases hydronephrosis, UTI, VUR, and improves kidney function. The procedure is well tolerated and reversible, with few complications and should be considered in children in whom conservative and medical treatment has failed (Rouzrokh et al., 2013).
The evaluation of temporary vesicostomy as a protector of upper urinary tract in children with voiding dysfunction and assessment the possible predictors of morphological and functional improvement of upper urinary tract have been little explored in the current literature.

The present work aimed to evaluate the outcomes of temporary vesicostomy in children with voiding dysfunction and to assess the possible predictors of morphological and functional improvement of upper urinary tract

\section{PATIENTS AND METHODS}

This retrospective study included the medical files of patients who underwent Vesicostomy using the Blocksom technique due to bladder outlet obstruction or dysfunction during the period from January 2014 to December 2019 in Urology Department at Al-Azhar University hospitals were evaluated.

A total of 63 males $(91.3 \%)$ and 6 females $(8.7 \%)$ patients including 25 cases diagnosed intrauterine and 44 cases diagnosed after delivery. The reason for applying this procedure was failure in clinical treatment defined by recurrent UTI, stable high degree vesicoureteral reflux (VUR), worsening hydronephrosis and renal function despite using CIC and anticholinergic drugs. All patients received prophylactic antibiotic after Vesicostomy. In this technique, the Vesicostomy was created from the bladder dome to minimize the risk of prolapse. Findings of ultrasonography (US), voiding-cysto-urethrography (VCUG), and static renal scintigraphy, and lumbosacral magnetic resonance imaging (MRI) 
in myelodysplastic cases were recorded. Creatinine clearance was measured based on Schwartz formula, and urine cultures were obtained before surgery. Urine culture and sonography checked every three months and, every six months during the follow-up. The patient was considered clinically improved when clinical symptoms disappeared and urine analysis revealed no pus cells.

The morphological improvement is considered when achieving the following criteria: Absence of additional renal scare, decrease in degree of hydronephrosis and reduction in degree of VUR. Functional improvement: is considered if there are decreases in serum creatinine and stabilization or improvement of glomerular filtration rate.A standard questionnaire was completed for all patients who included gender, age, and diagnosis, time of any surgical intervention, associated anomalies, and primary/secondary complications.

\section{Statistical analysis:}

All results were analyzed using the Statistical Package for the Social Sciences (SPSS) program, version 23. Independentsamples t-test of significance was used when comparing between two means. Mann Whitney U test was used for twogroup comparisons in non-parametric data. Paired sample t-test of significance was used when comparing between related samples. Comparison between two related samples for non-parametric data used Wilcoxon Rank Sum test. Chi-square (x2) test of significance was used in order to compare proportions between qualitative parameters. Linear regression: It was used to test and estimate the dependence of a quantitative variable based on its relationship to one or more independent variables. The confidence interval was set to $95 \%$ and the margin of error accepted was set to $5 \%$. P value $<0.05$ was considered statistically significant.

\section{RESULTS}

A total of 63 males $(91.3 \%)$ and 6 females $(8.7 \%)$ patients included 25 cases diagnosed intrauterine, and 44 cases diagnosed after delivery; the mean age of the total patients was $15.38 \pm 2.74$ (Months); the mean age of cases less than one year at the time of Vesicostomy was $2.78 \pm 0.32$ and the mean age of cases more than one year was $28.42 \pm 5.11$.
Twenty cases (29\%) had accidental discovered hydronephrosis, 22 cases $(31.9 \%)$ had recurrent UTI, 10 cases (14.5\%) had abdominal swelling, 8 cases $(11.6 \%)$ had recurrent fever since birth and 9 cases $(13 \%)$ had oliguria, elevated serum creatinine in (Table 1).

\section{Table (1): Different Presentations before Vesicostomy}

\begin{tabular}{|l|c|c|}
\hline Presentation & Frequency & Percent \\
\hline Accidental discovered hydronephrosis & 20 & 29.0 \\
\hline Recurrent UTI & 22 & 31.9 \\
\hline Abdominal Swelling & 10 & 14.5 \\
\hline Fever & 8 & 11.6 \\
\hline Oliguria and elevated serum creatinine & 9 & 13.0 \\
\hline Total & 69 & 100.0 \\
\hline
\end{tabular}


The etiology of hydronephrosis in the study was PUV and Neurogenic bladder and distributed as follow: 48 cases was
PUV and 21 cases was neurogenic bladder (15 cases were males and 6 cases were females) as shown in (Table2).

Table (2): Different etiology at the time of Vesicostomy

\begin{tabular}{|c|c|c|c|c|}
\hline Sex & Number & Etiology & Frequency & Percent \\
\hline Males $: 48$ & 48 & PUV & 48 & 69.5 \\
\hline Males: 15 & 15 & Neurogenic Bladder & 21 & 30.5 \\
Females:6 & 6 & Total & 69 & 100.0 \\
\hline & 69 &
\end{tabular}

The indication of vesicostomy in the study: $36(52.2 \%)$ cases were recurrent UTI. Thirty two males and 4 females, 23 $(33.3 \%)$ were worsening of hydronephrosis and renal function despite using CIC and anticolnergic drugs. Twenty one males and 2 females, 10 (14.5\%) were PUV not improved on vulgeration. Cases investigated laboratory with urine analysis, urine culture and sensitivity, $\mathrm{CBC}$, serum creatinine (S.cr).We found the mean S.cr of the cases was 1.75 and the most causative organism in the culture was E.coli. All cases were investigated radiologically with UIS, voiding cystourethro gram (VCUG), Magnetic Resonance Uorography (MRU) and renogram. According to VCUG, 37 $(53.6 \%)$ cases GVreflux 34 cases of them were males and 3 cases were females, 32 (46.4\%) cases G1V reflux 29 cases of them was males and 3 cases females. According to UlS, 55 (79.7\%) cases had G1V hydronephrosis 49 cases of them was males and 6 females, $14(20.3 \%)$ cases G111 hydronephrosis, all of them were males. According to MRU, 47 (68.1\%) cases sever hydroureteronephrosis 43 cases of them was males and 4 cases females, $22(31.9 \%)$ cases moderate hydroureteronephrosis 20 cases of them males and 2 females. According to renogram we found $38(55.1 \%)$ cases total GFR less than or equal 20 and 31 (44.9\%) cases total GFR more than 20. Seven $(10.1 \%)$ cases complicated with prolapse 5 of them male and 2 females, 8 (11.6\%) cases complicated with stenosis all of them was males, $10 \quad(14.5 \%)$ cases complicated with peristomal dermatitis all of them were males. Thirty four $(49.3 \%)$ cases closed after less than 6 months post vesicostomy, $25(36.2 \%)$ cases closed between 6-12 months post vesicostomy, $10(14.5 \%)$ cases closed after 12 month post vesicostomy. We found functional improvement in cases according to s.cr, urine culture, TLC. The mean s.cr before vesicostomy was 1.75 and improved gradually to 0.97 after 12 months of follow up PUScell decreases gradually from mean (44.35) down to mean (2.6), TLC from mean (13.06) down to (7.09).

According to US: $6(8.7 \%)$ cases grade 0 . $4(5.8 \%)$ cases $\mathrm{G} 1$ hydronephrosis all of them males. $26(37.7 \%)$ cases G2 hydronephrosis 23 of them males and 3 females. 18 (26.1\%) cases $\mathrm{G} \quad 3$ hydronephrosis $17 \mathrm{of}$ them males and 1 female. $15 \quad(21.7 \%)$ cases G4 hydronephrosis 13 of them males and 2 females.

According to MRU: 7 (10.1\%) cases all of them males with no HUN. 29 (42\%) cases mild HUN 26 of them males and 3 females. $20(29 \%)$ cases moderate HUN 19 of them males and 1 female. 13 (18.8\%) cases severe HUN 11 of them males and 2 females According to renogram: $6(8.7 \%)$ cases total GFR equal or less than 20. and $63(91.3 \%)$ cases total GFR more than 20. All cases in the study clinically improved according to symptoms of the patient depend on urine analysis and TLC as (Table 3). 
Table (3): Comparison of clinical parameters pre and post vesicostomy

\begin{tabular}{|c|c|c|c|c|c|c|}
\hline \multicolumn{7}{|c|}{ Paired Samples Statistics } \\
\hline \multicolumn{2}{|c|}{$\begin{array}{c}\text { Clinical Paired Samples } \\
\text { Statistics }\end{array}$} & Mean & $\mathrm{N}$ & SD & $\%$ change & $P$ value \\
\hline \multirow{2}{*}{ Pair 1} & $\begin{array}{l}\text { Pus cells before } \\
\text { vesicostomy }\end{array}$ & 44.35 & 69 & 33.23 & \multirow{2}{*}{-94.02} & \multirow{2}{*}{$P<0.01$} \\
\hline & $\begin{array}{l}\text { Pus cells After } \\
\text { vesicostomy }\end{array}$ & 2.65 & 69 & 1.74 & & \\
\hline \multirow{2}{*}{ Pair 2} & $\begin{array}{l}\text { TLC Before } \\
\text { vesicostomy }\end{array}$ & 13.06 & 69 & 4.44 & \multirow{2}{*}{-45.73} & \multirow{2}{*}{$P<0.01$} \\
\hline & $\begin{array}{l}\text { TLC After } \\
\text { vesicostomy }\end{array}$ & 7.09 & 69 & 2.47 & & \\
\hline
\end{tabular}

Sixty two $(89.9 \%)$ cases developed morphological improvement, while 7 according to VCUG.US and MRU (Table $(10.1 \%)$ of cases did not improve

4).

Table (4): VCUG parameters pre and post vesicostomy

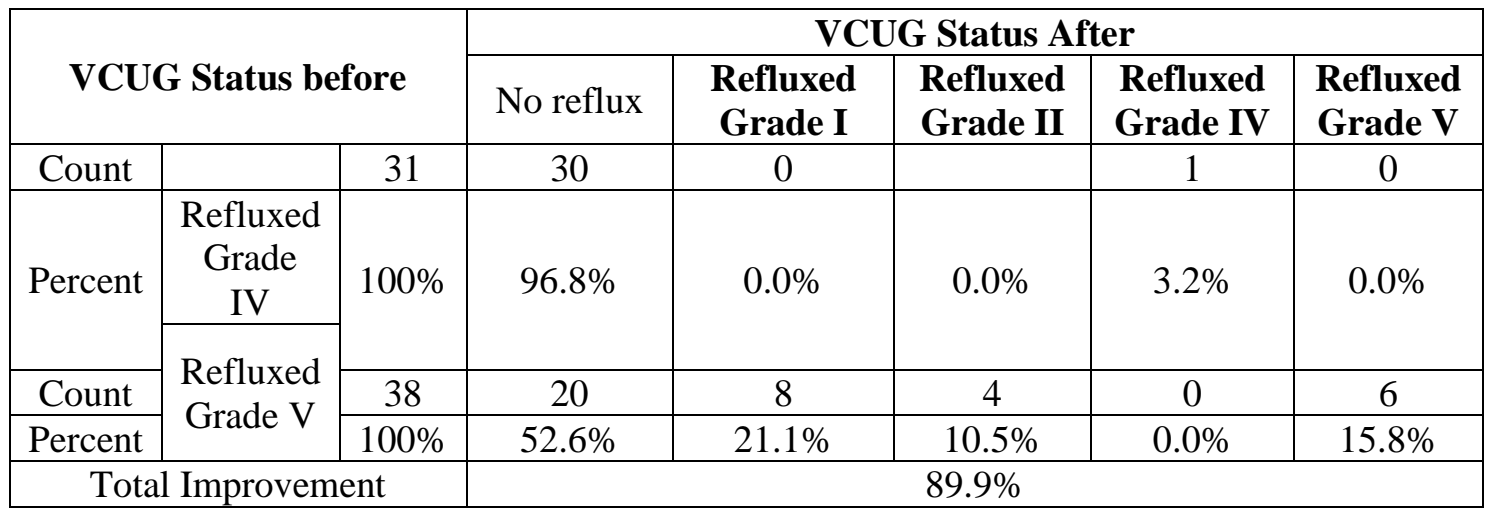

Eighty five cases (84\%) improved and 11 cases (16\%) not improved as regard renogram and S.cr (Table 5).

Table (5): Comparison of GFR pre and post vesicostomy

\begin{tabular}{|c|c|c|c|c|c|c|c|c|c|c|}
\hline & \multirow{2}{*}{$\mathrm{N}$} & \multirow{2}{*}{ Mean } & \multirow{2}{*}{ SD } & \multirow{2}{*}{ SE } & \multicolumn{2}{|c|}{$\begin{array}{l}95 \% \text { Confidence } \\
\text { Interval }\end{array}$} & \multirow{2}{*}{ Min. } & \multirow{2}{*}{ Max. } & \multirow{2}{*}{$\begin{array}{c}\mathrm{P} \\
\text { value }\end{array}$} \\
\hline & & & & & & $\begin{array}{l}\text { Lower } \\
\text { Bound }\end{array}$ & $\begin{array}{l}\text { Upper } \\
\text { Bound }\end{array}$ & & & \\
\hline \multirow{3}{*}{$\begin{array}{l}\text { Total } \\
\text { GFR } \\
\text { Befor }\end{array}$} & Improved & 58 & 24.8 & 11.6 & 1.5 & 21.9 & 27.8 & 13.0 & 52.0 & \multirow{6}{*}{$\mathrm{P}<0.01$} \\
\hline & $\begin{array}{c}\text { Not } \\
\text { Improved }\end{array}$ & 11 & 26.9 & 12.1 & 4.6 & 15.7 & 38.1 & 14.7 & 49.7 & \\
\hline & Total & 69 & 25.0 & 11.5 & 1.4 & 22.3 & 27.8 & 13.0 & 52.0 & \\
\hline \multirow{3}{*}{$\begin{array}{l}\text { Total } \\
\text { GFR } \\
\text { After }\end{array}$} & Improved & 58 & 53.7 & 20.6 & 2.6 & 48.5 & 59.0 & 13.7 & 110.0 & \\
\hline & $\begin{array}{c}\text { Not } \\
\text { Improved }\end{array}$ & 11 & 24.3 & 10.9 & 4.1 & 14.2 & 34.4 & 10.0 & 43.0 & \\
\hline & Total & 69 & 50.8 & 21.7 & 2.6 & 45.5 & 56.0 & 10.0 & 110.0 & \\
\hline
\end{tabular}


There was a significant difference between GFR improved and not improved patients according to abdominal Swelling, Pus cells and MRU findings.

Abdominal Swelling, MRU and Pus cells in the urine analysis were entered in multivariate logistic regression model; every one of these factors was significant i.e. independently affects GFR improvement (Table 6).

Table (6): Multivariable regression analysis of factors affecting GFR improvement

\begin{tabular}{|c|c|c|c|c|}
\hline \multirow{2}{*}{ Factors } & \multirow{2}{*}{ P value } & \multicolumn{3}{|c|}{ Odds Ratio } \\
\cline { 3 - 5 } & & Exp. (B) & Lower & Upper \\
\hline Abdominal Swelling & 0.028 & 0.860 & 0.533 & 2.305 \\
\hline MRU: Severe HUN & 0.039 & 0.634 & 0.393 & 1.699 \\
\hline Pus cells before & 0.043 & 0.848 & 0.526 & 2.273 \\
\hline
\end{tabular}

\section{DISCUSSION}

Vesicostomy is considered a temporary urinary diversion. Some authors suggested it be a permanent diversion, mainly in patients who refuse CIC or those who choose an incontinent diversion (Hutcheson et al., 2010).

Our study included 69 patients (63(91.3\%) males and 6(8.7\%) females) who underwent cutaneous vesicostomy due to failure in clinical treatment defined by worsening hydronephrosis, recurrent UTI, stable high-degree VUR, deteriorating kidney function, and noncompliance with CIC anticholinergics.

Forty four $(63.8 \%)$ cases not developed any complications, while $7(10.1 \%)$ cases (5 male and 2 females) complicated with prolapse, $8(11.6 \%)$ cases complicated with stenosis all of them were males, and $10(14.5 \%)$ cases complicated with peristomal dermatitis.

Other studies reported that a total number of 53 patients, Complications related to vesicostomy were dermatitis in 10 cases, mild stomal stenosis in 3 cases and mucosal prolapse in 2 cases. 33 patients had renal failure (Rouzrokh et al., 2013).
In other study, Complications after Vesicostomy were stoma stenosis in 9 cases $(11.25 \%)$, mucosal prolapse in 6 cases $(7.5 \%)$, dermatitis in 3 cases $(3.75 \%)$, and febrile UTI in 4 patients (5\%), one of whom needed to be readmitted to the hospital (Lukong et al. 2014).

Also, Prudente et al. (2009) reported that the complications of the surgery were stenosis in 8 patients $(38.1 \%)$, dermatitis in $5(23.8 \%)$, and mucosal prolapse in 6 (28.6\%). Among children with prolapse, 5 presented dermatitis. On the other hand, 3 patients with stenosis presented prolapse after surgical correction.

In our study, 12 months post operatively, the mean s.cr declined from $1.75 \pm 0.13 \mathrm{mg} / \mathrm{dl}$ to $0.97 \pm 0.74 \mathrm{mg} / \mathrm{dl}$, the mean pus cells count dropped from $44.35 \pm 4.00$ cell $/ \mathrm{HPF}$ to $2.6 \pm 1.74$ cell $\mathrm{HPF}$, and the mean TLC cumm declined from $13.06 \pm 0.53$ cumm to $7.09 \pm$ 2.47 cumm.

In their study, Rouzrokh et al. (2013) reported that all cases that had high level of creatinine (1.5-5.9) preoperatively, $90.5 \%$ of them decreased to normal after vesicostomy. 
As regard UTI, there was a complete improvment in all cases post operatively in our study.

In their study, Prudente et al. (2009) reported that after vesicostomy, 8 children (38.1\%) demonstrated a decrease of UTI without suppressive antibiotic therapy, while the others needed continuous antibiotic therapy because of more than 1 UTI episodes per year.

Fourteen patients $(66.7 \%)$ presented VUR before the operation (10 bilateral and 4 unilateral), all with grades 3 or 4 . Complete resolution was observed in 4 unilateral cases and improvement to grades 1 or 2 in 6 bilateral cases. No impairment in 4 bilateral cases which maintained grade 3 or 4 (Prudente et al., 2009).

In our study, 31 patients presented with grade 4 VUR. Complete resolution was observed in 30 patients and one patient maintained grade 4 VUR. While, 38 patients presented with grade 5 VUR. Complete resolution was observed in 20 patients, 12 patients improved ( 8 patients turned into grade $1 \mathrm{VUR}, 4$ patients turned into grade 2 VUR), and 6 patients still had grade 5 VUR.

In our study, $62(89.9 \%)$ cases developed improvement in $\mathrm{HN}$ and 7 $(10.1 \%)$ of cases not improved, while Rouzrokh et al. (2013) reported 80\% cure rate in $\mathrm{HN}$.

Westney (2010) reported an objective improvement of $\mathrm{HN}$ ranging from $85 \%$ to $100 \%$ and stabilization of kidney function, evaluated by renal scintigraphy, of around $88 \%$ has been detected following vesicostomy.
Prudente et al. (2009) reported that there was no postoperative impairment in 20 children $(95.2 \%)$ as regard renal function, while in our study, 85 cases (84.1\%) developed GFR improvement, while 11 cases (15.9\%) not improved.

\section{CONCLUSION}

Vesicostomy is a simple surgery that protects upper urinary tract, decreases hydronephrosis, UTI, VUR, and improves kidney function. Vesicostomy is a simple urinary diversion, showing encouraging results towards safeguard of kidney function. Furthermore, the procedure has received rave reviews from the caregivers, and therefore, it has become a viable choice for children with neurological or other voiding dysfunctions or those that do not respond to conservative treatment. The outcome of vesicostomy is affected by multiple factors as the age of the patient, abdominal Swelling, MRU findings and Pus cells in the urine analysis. The outcome of vesicostomy is affected by multiple factors as the age of the patient, abdominal Swelling, MRU findings and Pus cells in the urine analysis.

\section{REFERENCES}

1. Coran, A. G., A. Caldamone, N. S. Adzick, T. M. Krummel, J.-M. Laberge and R. Shamberger (2012): Pediatric surgery E-book, Elsevier Health Sciences.

2. Howe, A., Kozel, Z., \& Palmer, L. (2017): Robotic surgery in pediatric urology. Asian Journal of Urology, 4(1), 55-67.

3. Hutcheson, J. C., C. S. Cooper, D. A. Canning, S. A. Zderic and H. M. Snyder (2010): "The use of vesicostomy as permanent urinary diversion in the child 
with myelomeningocele." The Journal of urology 166(6): 2351-2353.

4. Lopez Pereira, P., E. Jaureguizar, M. Martinez Urrutia, $C$. Meseguer and $M$. J. P. t. Navarro (2000): "Does treatment of bladder dysfunction prior to renal transplant improve outcome in patients with posterior urethral valves?" 4(2): 118122.

5. Lukong, C. S., Ameh, E. A., Mshelbwala, P. M., Jabo, B. A., Gomna, A., Anumah, M. A.,... \& Mfuh, A. Y. (2014): Role of vesicostomy in the management of posterior urethral valve in Sub-Saharan Africa. Journal of Pediatric Urology, 10(1), 62-66.
6. Prudente, A., L. O. Reis, R. de Paula França and M. J. U. J. Miranda (2009): "Vesicostomy as a protector of upper urinary tract in long-term follow-up." 6(2): 96-100.

7. Rouzrokh, M., A. Mirshemirani, A. Khaleghnejad-Tabari, N. Sadeghian, L. Mohajerzadeh and M. J. I. J. o. P. Mohkam (2013): "Protective temporary vesicostomy for upper urinary tract problems in children: a five-year experience." 23(6): 648.

8. Westney, O. L. J. U. C. (2010): "The neurogenic bladder and incontinent urinary diversion." 37(4): 581-592. 
فغر المثانة المؤقت للاطفال الذين يعانون من خلل وظيفي مفرط في التبول: التنبؤات المحتملة بتحسن شكلي ووظفيفي في الجهاز البولي العلوي

احمد حسين عكاثة، حسين عبد الله جلال، السيد محمد صالح

قسم جراحة المسالك البولية ، كلية الطب ، جامعة الأزهر (القاهرة)

الناثر : احمد حسين عكاثة، موبايل: 01008072741

E-mail: aokasha2016@gmail.com

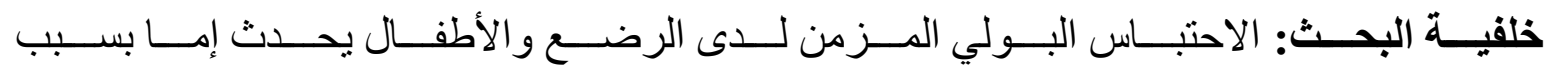

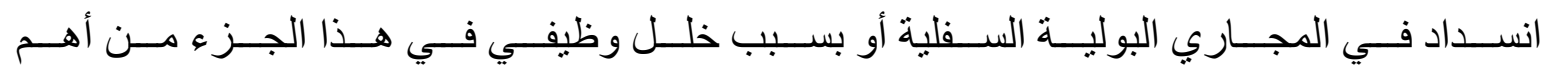

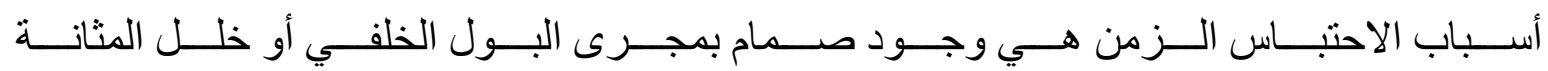

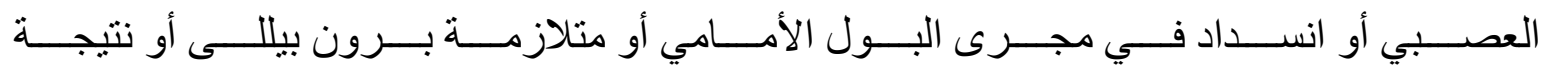

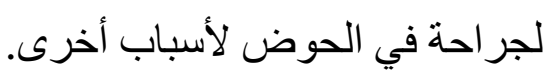

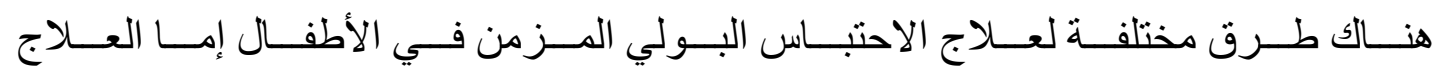

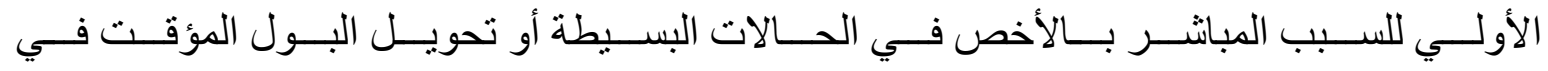

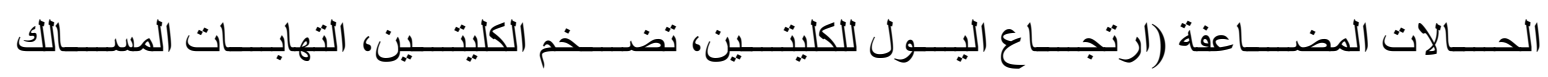

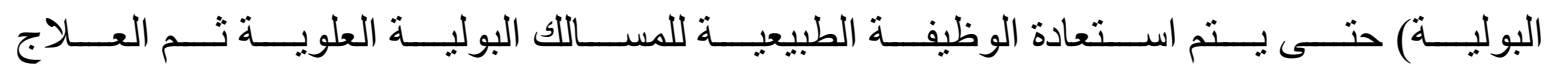

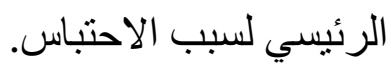

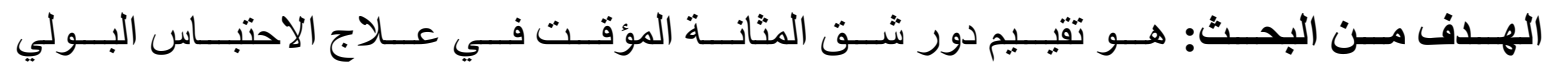

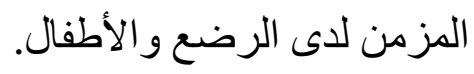

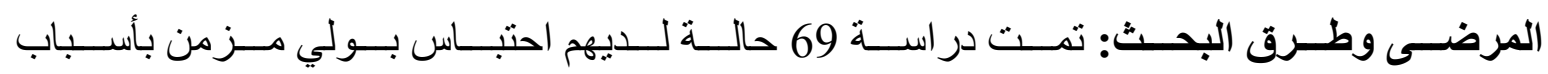

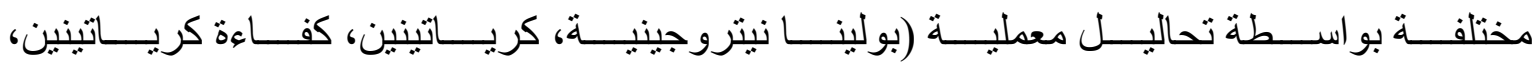

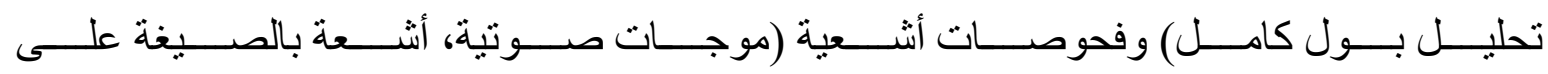

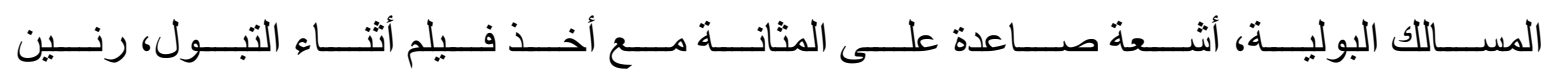

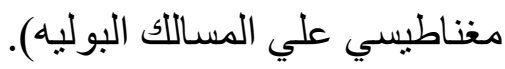




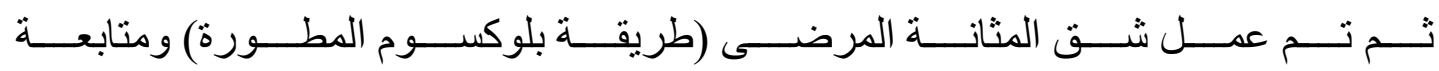
المرضى بواسطة التحاليل المعملية و الفحوصات الأشعية).

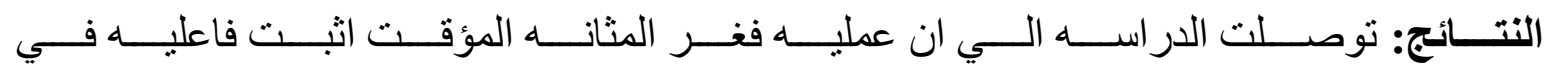

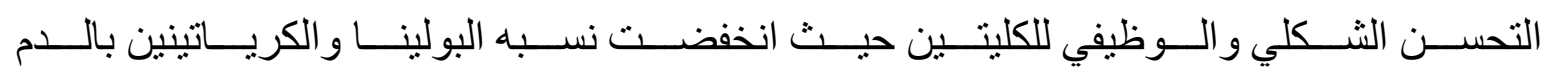

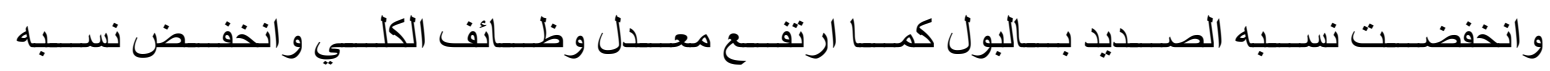
الارتجاع ع الكليتين وظهر تحسن ملحوظ في نسيج الكلي.

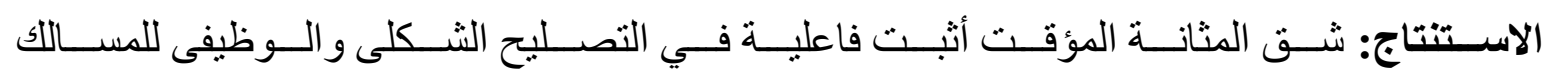

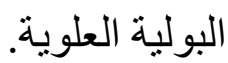

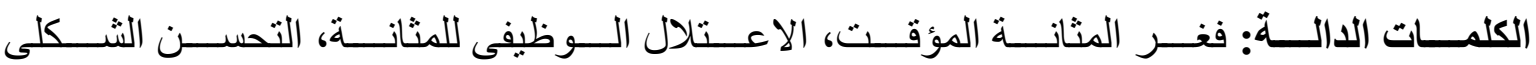
و الوظيفى للمسالك البولية العلوية. 